\title{
MODELO CONCEPTUAL DE LA EVOLUCIÓN-CRECIMIENTO CON DIVERSIDAD COMERCIAL RURAL: PLAZA EJIDAL GANADERA PUENTE SAN BERNABÉ, ESTADO DE MÉXICO
}

\author{
CONCEPTUAL MODEL OF EVOLUTION-GROWTH WITH RURAL \\ COMMERCIAL DIVERSITY: PLAZA EJIDAL GANADERA PUENTE \\ SAN BERNABE, STATE OF MEXICO
}

\author{
Eduardo Teófilo-Salvador*
}

\section{RESUMEN}

El objetivo de esta investigación fue generar el modelo conceptual que ha permitido la evolución y el crecimiento del Tianguis y Plaza Ganadera Ejidal Puente San Bernabé en Almoloya de Juárez, como punto de encuentro para la comercialización de productos diversos. Se inició con la ubicación del sitio dentro de un marco regional y estatal; se identificaron los giros comerciales y se dio el reconocimiento de los actores involucrados. Se realizaron aforos de afluencia peatonal y se revisó del crecimiento superficial en el tiempo; finalmente, se evaluó la información recolectada para formular la propuesta de modelo conceptual. Se ha obtenido que los giros comerciales han sido el motor de supervivencia, aún por encima de otros mercados cercanos, la accesibilidad de precios y la disponibilidad de espacios, verificado al realizar ciclos iterativos en el modelo conceptual. Sin embargo, quienes intercambian sus productos son los menos favorecidos. De esta forma, a pesar de la marginación, la competitividad con comercios establecidos, la volatilidad de los precios y la ubicación rural, el actual Tianguis ha tenido un crecimiento de más del $260 \%$ en los últimos 17 años gracias a la diversidad de productos que se comercializan cada lunes.

PALABRAS CLAVE: MÉXICO * OFERTA Y DEMANDA * COMERCIO * MERCADO * MARGINALIDAD

Universidad Autónoma del Estado de México, Ciudad de México, México.

mca.ts.eduardo2015@gmail.com

https://orcid.org/0000-0001-8794-2938 


\section{ABSTRACT}

The objective of this research was to determine the conceptual model that has allowed the evolution and growth of the Tianguis and Plaza Ganadera Ejidal Puente San Bernabe in Almoloya de Juárez, as a meeting point for the commercialization of diverse products. The elaboration of the conceptual model started with locating the site within a regional and state framework, identifying the commercial business, and recognizing the actors involved. With this, pedestrian traffic gauges and review of surface growth were made over time. Finally, it was all evaluated to formulate the proposed conceptual model. It was found that commercial business is the engine of survival, above other nearby markets, due to the accessibility of prices and availability of spaces, verified by iterative cycling the conceptual model. However, those who exchange their products are the least favored. In this way, despite the marginalization of competitiveness with established businesses, price volatility, and the rural location, the current Tianguis has had a growth of more than $260 \%$ in the last 17 years, as a result of the diversity of products that are marketed every Monday.

KEYWORDS: MEXICO * SUPPLY AND DEMAND * TRADE * MARKET * MARGINALIZATION

\section{INTRODUCCIÓN}

En un país civilizado, los mercados son poco permutables con el trabajo para generar ganancias, por lo que los productos son la base para la venta, así parte de la riqueza o pobreza son condiciones progresivas de una sociedad (Smith, 1794). En este contexto, los tianguis o mercados tradicionales en México han sido $y$ siguen siendo un modelo en el que los vendedores y compradores negocian productos, alimentos y artículos. Esto suele hacerse a través de prácticas como el trueque o el intercambio; los tianguis o mercados tradicionales constituyen una aproximación a una realidad dinámica al ser un espacio de intercambio comercial, con presencia $y$ disponibilidad de recursos o productos, su manejo, oferta y demanda, necesidades $y$ reglas en torno a la forma de compra-venta (Arellanes et al., 2017). Además, según García et al. (2016), los tianguis o mercados generan una relación económico-social. Así, todo intercambio propicia un acercamiento entre productores $y$ consumidores, lo que representa un tipo de convivencia en especial para específicos sectores de la población. De tal manera, esta forma de comercio permite manifestar expresiones particulares de un sito o una región a través del tiempo.

En el México antiguo, los tianguis fueron vistos como puntos de reunión y comunicación por reunir a tantas personas, lo cual beneficiaba a iglesias y tiendas abarroteras (Villegas, 2010), ya que los mercados se instalaban generalmente en centros poblacionales. A pesar del tiempo $y$ de crecimientos urbanos se han mantenido, pero con necesidades de actualización e innovación, Incluso, han surgido nuevos mercados, lo que ha generado la adaptación de nuevos compradores y nuevos productos en función de su ubicación y administración (Rubio, 2013). Por este motivo, los actuales tianguis o mercados deben analizarse desde perspectivas multidisciplinarias, que permitan concebir su integración, crecimiento y evolución geográfica y social a través del tiempo. A partir de esto, se evalúa su retiro, permanencia o desarrollo, para con ello identificar el rol de los actores participantes, así como el consumo, para así desarrollar una planificación mediante Ingeniería, Geografía y Sociología.

Con base en lo anterior, el mercado o tianguis debe considerarse como un sistema económico complejo. La diversidad de factores involucrados que van desde el sitio de ubicación, administración, productos ofertados y productos demandados, bajo el intercambio bien por bien, por dinero o por servicios, permite la interacción sociocultural entre los sujetos $y$ los productos que deriva en relaciones sociales (Licona, 2014). Malinowski y de la Fuente (1957) analizaron espacios públicos, no políticos, pero significativos, para estudiar modos tradicionales, cambios $y$ desarrollos de cultura 
indígena y mestiza. Por tanto, es necesario reconocer los diversos tipos de mercados, de lo general a lo particular, considerando los giros, su ubicación y la manera en que impactan en el desarrollo de la sociedad $y$ de los comerciantes.

En este contexto, la globalización ha permitido la creación de tianguis ecológicos (plantas, hortalizas), granjeros (comercialización de animales domésticos $y$ de corral) y alternativos (comercialización de artículos de variedad según época y sitio), debido a la necesidad en la diversificación de productos, así como a la integración de nuevos productores. Con lo anterior, se ha buscado mejorar la calidad de vida de los actores, brindando protección y reducción de pobreza, así como acercar a los consumidores $y$ ofertar el consumo de alimentos locales, dejando a un lado los productos de empresas extranjeras (Escobar-López et al., 2016). Otro caso es la presencia de tianguis orgánicos (comercialización de frutas y verduras, semillas de una región) como un sistema de producción, visto desde los ingresos de los pequeños agricultores, asalariados rurales e, incluso, en el desarrollo rural. Por tanto, los productores $y$ las personas consumidoras han sido clave para la sostenibilidad económica, la cual aumenta a medida que los productores amplían su producción y diversifican sus canales de comercialización (Bustamante-Lara y Schwentesius-Rindermann, 2018). A raíz del crecimiento y las necesidades de control de la gran variedad de tianguis presentes en México, organismos como la Red Mexicana de Tianguis y Mercados Orgánicos (REDAC) se han dado a la tarea de guiar a los productores a través de un comité coordinador y apoyo técnico enfocado a productos orgánicos.

Otro tipo es el mercado de productores, los cuales por mayor rentabilidad económica $y$ presencia de servicios se ubican en zonas urbanas. Así, los productores y transformadores de mercancías ofrecen productos (de elaboración industrial) por la competitividad a escalas limitadas; sin embargo, esta forma de mercados permite la vinculación con centrales de abasto o supermercados (García et al., 2017).

En el Estado de México, las necesidades de consumo de bienes, servicios y productos no pueden ser cubiertas por un solo grupo de población. Por esta razón, son necesarios la venta, la compra y el intercambio de unidades de consumo. De este modo, la pluralidad $-y$ primordialmente la necesidad- ha obligado a personas originarias de diversos poblados a ofertar productos, aun aquellos de consumo propio. Así, entonces, han sido y siguen siendo ofrecidos en distintos tianguis como en el Valle de Toluca (Arteaga, 1993). Esta zona ha sido de interés por la producción de maíz, con alta productividad agrícola por los pastizales, ricas tierras para granjería, con agua, buen clima y entorno ecológico, lo cual ha favorecido la comercialización en esta región (Quezada, 1995).

Un tianguis de gran importancia es el tradicional mercado de Palmillas (antes en el Mercado Juárez). Este tianguis desempeña una importante función en el desarrollo económico de la zona centro del Valle de Toluca debido a la gran cantidad volúmenes, así como, a la variedad de mercancías y productos que se comercializan cada viernes, en especial, prendas de vestir (Aranda, 2005). Sin embargo, las reubicaciones, los procesos de urbanización, la industrialización y la modernización han generado que desaparezca la venta de ganado $y$ aves. Como consecuencia, esto ha llevado a la introducción de nuevos bienes, desplazando así productos de origen natural (González y Vega, 2016). Aunado a ello, la situación que se vive en el actual mercado Juárez en la ciudad de Toluca lleva a la necesidad de establecer áreas de venta controlada debido a las pocas oportunidades o la falta de información para la inserción formal de comerciantes más vulnerables que ofertan productos de temporada (Almazán, 2017).

Otro tianguis es el que se realiza los lunes en el centro de Ixtlahuaca de Rayón, que cuenta con una plaza de aves a la salida norte de la zona urbana, lo que para González y Vega (2016), aun es una marca precisa del mundo indígena; es decir, de grupos oferentes que provienen de comunidades particulares a ofrecer sus animales. Dentro de esta misma región del Valle de Toluca-Ixtlahuaca se localiza la plaza ganadera ejidal "Puente San Bernabé". Dicha plaza es de relevancia y gran impacto regional debido a que concentra una actividad comercial 
de más de cuatro regiones, genera una derrama económica importante, permite el abasto $y$ mejora la genética del ganado (PDMAJ, 2016). Anteriormente era más notable la adquisición de animales para la labranza del campo. Debido a la escasez de recursos económicos y de medios de transporte, los productores intercambiaban sus animales para regular el consumo y el trabajo (Cruz, 2003). El anterior tianguis ha sido objeto de estudio en el contexto ganadero especialmente, donde han participado la Secretaría de Ecología del Estado de México y representantes gubernamentales para proponer soluciones a las problemáticas ganaderas (Córdova et al., 1997; López et al., 1994).

De esta forma, la plaza ganadera San Bernabé inició siendo objeto para animales de granja; sin embargo, actualmente es de gran importancia debido al crecimiento acelerado que ha presentado en los últimos 20 años. Su expansión ha sobrepasado los límites originales $y$ se ha diversificado, mediante la oferta de productos (giros mercantiles) de otros mercados en menor escala. Por estas razones, el objetivo de la investigación fue generar el modelo conceptual que ha permitido la evolución y el crecimiento del Tianguis y Plaza Ganadera Puente San Bernabé en Almoloya de Juárez como punto de encuentro para la comercialización de productos diversos. Para dar cumplimiento, en el trabajo de campo se ha considerado la interrelación entre observación superficial, el registro de las acciones y el análisis teórico (Malinowski y de la Fuente, 1957).

\section{METODOLOGÍA}

El sitio de estudio es conocido como Tianguis y Plaza Ganadera Ejidal Puente San Bernabé, localizado en el Municipio de Almoloya de Juárez con las coordenadas $19^{\circ} 28^{\prime} 07.97^{\prime \prime}$ N, 994409.14" O y a 2562 msnm. Los días lunes es un punto de encuentro de productores, consumidores $y$ visitantes, ya que se ubica en la intersección del km 9.46 de la carretera libre Toluca-Atlacomulco y la carretera a Mayorazgo de León, como se aprecia en la figura 1 . Según el mapa de clasificación territorial del Plan de Desarrollo Urbano de 2008, el sitio se encuentra dentro del área urbanizable.

Para iniciar la investigación, según lo estipulado por García et al. (2016), fue necesario seleccionar los tianguis con círculos de producción y consumo para el corredor Atlacomulco-Ixtlahuaca-Toluca. Por tanto, se realizó una ponderación local, regional y municipal de tianguis o mercados cercanos al sitio de estudio, considerando la variabilidad espacial y temporal; es decir, se localizaron y visitaron los puntos de compra-venta más cercanos con radios de: 5, 10, 20, 50 y $100 \mathrm{~km}$ y que estuvieran abiertos los días: lunes, martes, miércoles, jueves, viernes, sábado y domingo. 
Figura 1

Localización del sitio de estudio con crecimiento superficial ocupando áreas Años 1950 a 2020

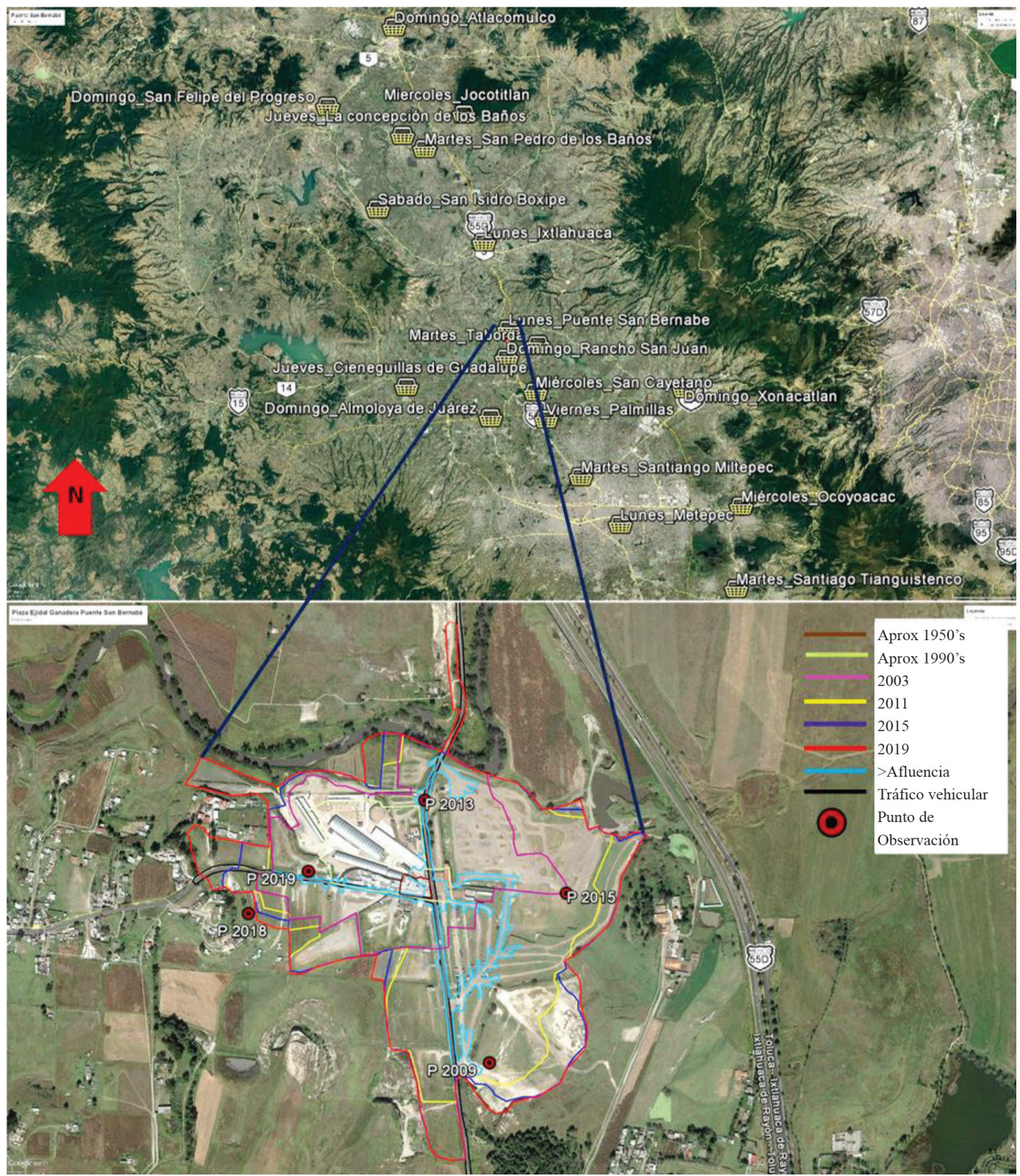

Nota. Elaboración propia con apoyo de Google Earth Pro 2019.

Cabe señalar que la información se obtuvo por diversas fuentes que incluyen: pláticas con vecinos originarios del sitio, consumidores, productores, así como de fuentes relevantes reportadas en notas periodísticas, documentación digital (artículos científicos, reportes) y mapas satelitales con evolución temporal desde 1950 al 2020 como se aprecia en 
la figura 1, para lo cual se trazaron polígonos para diferentes años. Adicionalmente, en septiembre y octubre de 2009, se realizaron visitas de reconocimiento. En 2013, 2015 y 2018 se hicieron recorridos mensuales para reconocer las principales rutas de mayor afluencia peatonal. Finalmente, de diciembre de 2019 a marzo de 2020 se frecuentó todos los lunes para recolectar datos de productos de venta, afluencia peatonal y algunos precios. De forma complementaria fue necesario instalar un puesto para la venta de productos de hogar, cosméticos, de cocina, ropa de reúso, artículos agrícolas y chácharas (artículos y accesorios antiguos, de bajo valor o precio que pueden servir como repuesto, ajustes o adaptaciones), con el fin de observar y evaluar la volatilidad de precios al compararlos con los de otros puntos de venta más alejados dentro del mismo tianguis.

\section{1) GIROS DEL TIANGUIS}

Según González y Vega (2016), un tianguis no es comercio informal, ya que pueden existir diversas actividades económicas con articulaciones en el mercado global. Por tanto, esto permite que se pueda convivir y competir con otras formas de mercado como los fijos, los supermercados $y$ los establecimientos de mercado de élite. Por lo anterior, en este apartado se reconoció e identificó las formas en que los productores, los comerciantes y los consumidores se concentran cada lunes para demandar $y$ ofertar diversos productos $y$ servicios en la Plaza Ejidal Puente San Bernabé.

Al identificar los diferentes tipos de giro comercial, esto permitió determinar el valor de importancia de las áreas de venta, presencia peatonal en el mercado y la temporalidad; es decir, identificar cómo cambian los productos que se ofertan según la época del año. Para lo anterior fue necesario realizar diversos recorridos en toda la superficie del tianguis en diferentes horarios $y$ trayectorias. Mediante la observación se identificó las maneras en que se agrupan los comerciantes lunes con lunes $y$, con ello, los distintos giros que se ofertan en la plaza.

Adicionalmente, debido a causas de contingencia COVID-19 se realizó una breve entrevista a diversos actores dentro del tianguis.
Por medio de Excel se recopilaron los datos: edad, procedencia, nivel de estudios, motivo de visita, recurrencia al tianguis, grado de satisfacción y otros tianguis visitados. Esta información se sistematizó para reconocer el perfil de los actores para analizar cómo influye este perfil en la integración del mercado. Además, lo anterior constituiría una fuente importante que hace referencia a la parte social, ya que los grupos integradores de los tianguis fueron diferentes según la observación de años previos, desde la forma de vestir, de convivir y de expresarse con los demás.

\section{2) AFOROS PEATONALES}

Se registró el aforo peatonal para estimar la concentración de personas que concurren al tianguis en un lunes normal, en lunes de día no laboral (feriado) y un lunes de vacaciones de fin de año. Para lo anterior, en el puesto instalado se contabilizó el número de peatones que ingresaron por la carretera a Mayorazgo de León, además de las personas que ingresaron por la zona norte en dirección al punto de observación de 2013 y del lado sur en dirección al punto de observación de 2009. En los tres casos, la afluencia peatonal iba con dirección hacia la intersección de la carretera libre Toluca -Atlacomulco- carretera a Mayorazgo de León. Los registros se tomaron desde las 7 a.m. hasta la hora de retiro de la mayoría de los puestos instalados. Finalmente, los datos obtenidos se capturaron y graficaron en una hoja de Excel.

\section{3) CRECIMIENTO SUPERFICIAL}

A partir de información obtenida de entrevistas con vecinos del lugar, del Plan de Desarrollo Municipal (Ayuntamiento Constitucional de Almoloya de Juárez, 2016), y concretamente del Google Earth Pro 2019, se realizó una regionalización del crecimiento superficial que ha presentado el Tianguis (figura 1). Esto se llevó a cabo tomando como base las imágenes cartográficas de los años 2003, 2011, 2015 y 2019, para lo cual también sirvieron los puntos de observación desde 2009, tal como se ilustra 
en la figura 2. Adicionalmente se compararon los datos obtenidos dentro de un marco local con base en los giros dentro del mismo mercado; luego se compararon con los datos ofertados por otros mercados cercanos dentro del corredor Toluca-Atlacomulco como: Almoloya de Juárez, Jocotitlán, Ixtlahuaca y Palmillas (Toluca), por su relevancia municipal.

Figura 2

Recorridos de visualización

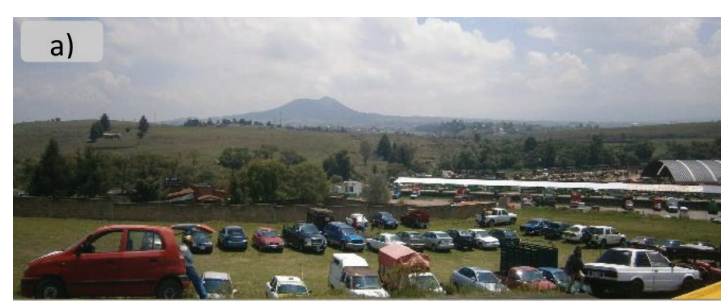

c)
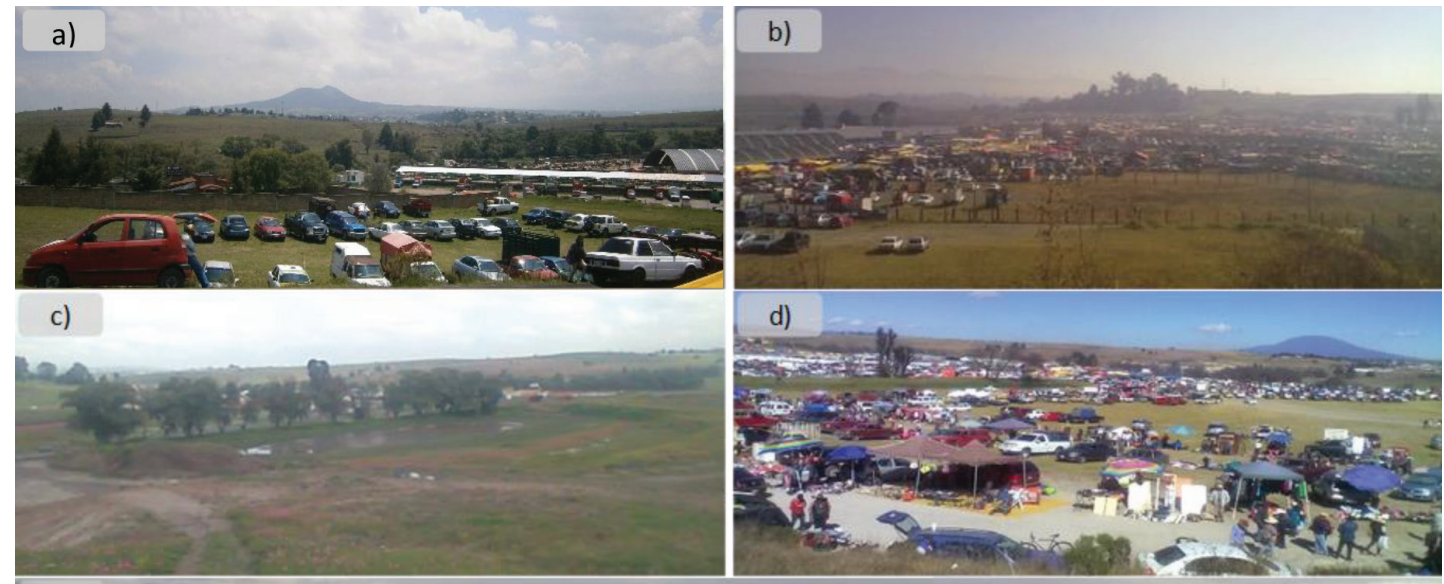

d)

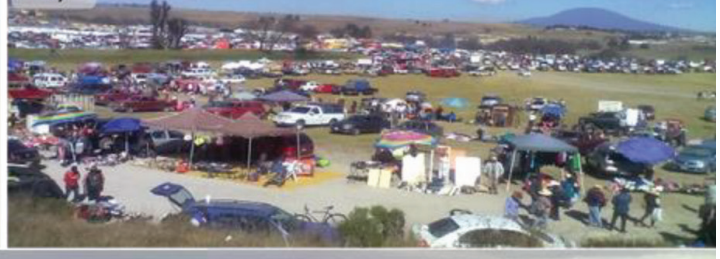

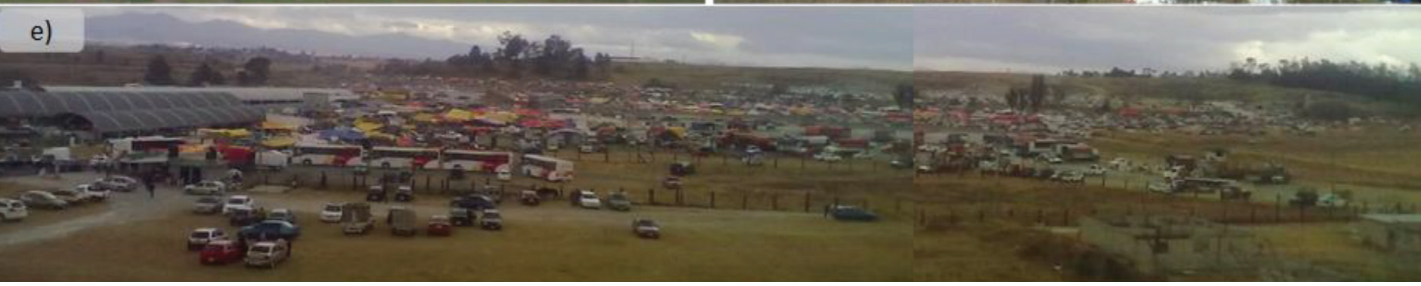

Nota: a) 2020 vista al norte, b) 2013 al lado oeste, c) 2009 lado sureste, d) 2019 lado sureste y, e) 2020 panorámica en un día feriado.

\section{PLANTEAMIENTO DEL MODELO CONCEPTUAL}

Para el diseño del modelo conceptual se tomaron en consideración todos los posibles factores geográficos, ambientales, sociales $y$ económicos que influyen dentro del sistema. Esta valoración se hizo a partir de lo establecido por Sales y Martínez (2014), quienes afirman que las adaptaciones socioculturales ajustan también los recursos naturales para el desarrollo económico y social de un sitio. Por tanto fue necesario analizar las fotografías, imágenes satelitales, documentación, recorridos y reconocimiento de los actores del sitio de estudio, con el fin de idealizar el funcionamiento que ha seguido el tianguis y la manera en que esto ha influido en su evolución y su crecimiento.

Cabe señalar que, hasta la fecha, no existe documentación científica asociada al modelo referente a este sitio de estudio. Esta carencia se debe a que, en la mayoría de los casos reportados asociados a tianguis, estos varían en factores como: posición geográfica, sector involucrado, giros comerciales lo cual provoca que cada modelo sea particular y propio de cada sitio. Además, cada investigación se realiza de acuerdo con el área de interés. En este estudio se revisan temáticas multidisciplinarias e interdisciplinarias, ya que aplicadas en conjunto aportan una concepción diferente. 


\section{RESULTADOS Y DISCUSIÓN}

Con respecto a la ponderación inicial para resaltar la importancia del sitio de estudio, en la Tabla 1 se muestra un cuadro comparativo de las diferencias y similitudes entre los mercados más próximos en el corredor TolucaAtlacomulco. Esta tabla se elaboró partiendo de los datos reportados por González y Vega (2016), los obtenidos en el presente estudio y de las observaciones en tianguis cercanos. Se realizó una evaluación desde las categorías de nula hasta muy alta según las percepciones y datos consultados, bajo los criterios de venta, superficie de comercialización y conectividad. 
Modelo conceptual de la evolución-crecimiento con diversidad comercial rural...

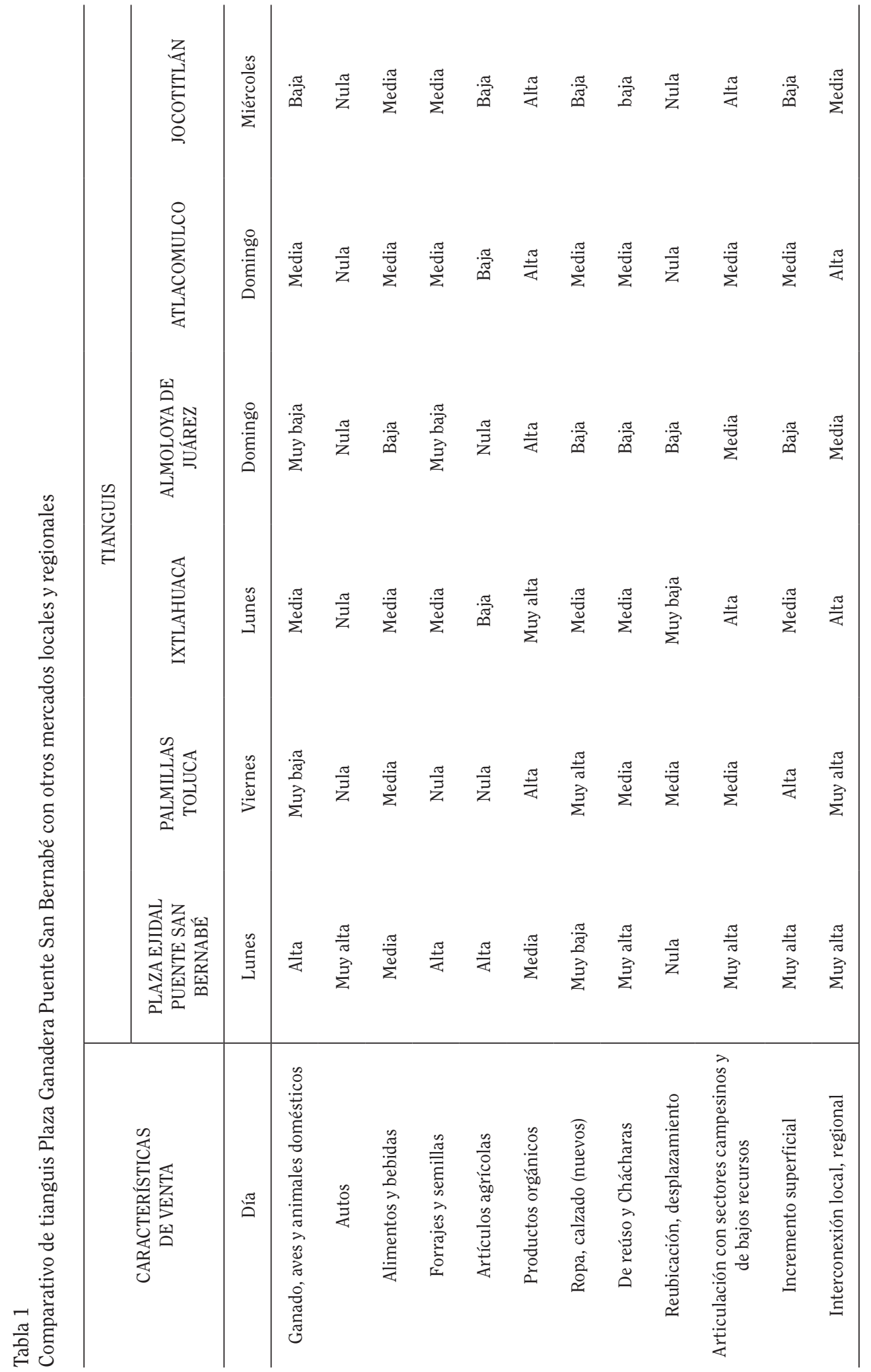


A partir de la tabla 1 es posible afirmar que la competitividad con mercados y tiendas comerciales establecidas son un obstáculo para el crecimiento; sin embargo, la diversificación de productos es el principal atractivo para que se mantengan, evolucionen en giros mercantiles y crezcan superficialmente - como ha sucedido en el Tianguis y Plaza Ganadera Ejidal Puente San Bernabé-. Adicionalmente, la presencia de áreas libres y áreas sin urbanización ha permito su expansión, lo que también ha favorecido a los vecinos del lugar mediante la prestación de servicios. La consolidación del tianguis ha generado que las periferias rurales se vean beneficiadas $y$, con ello, el establecimiento de comercios fijos y móviles, así como de renta de espacios fijos para ciertos vendedores. En otras palabras, las prácticas rurales de la zona han influido para mantener este mercado rural en el tiempo.

\section{1) GIROS DEL TIANGUIS}

La Plaza Ganadera Ejidal Puente San Bernabé inició con la venta de pollos, guajolotes $y$, posteriormente, de cerdos y borregos a las orillas de la carretera Ixtlahuaca-Toluca hace más de 70 años. Luego, se incorporó ganado vacuno, asnos y equinos. Actualmente, el comercio se ha diversificado con la venta de animales domésticos, animales de corral, aves y ganado de pastoreo. De todos los tipos mencionados, el ganado vacuno es de los más rentables por derivados como productos de alimentación artesanal, siendo de gran importancia en la mayoría de los tianguis del Valle de Toluca. Cada semana se concentran más de 10 mil cabezas de ganado de diferentes estados para comercializar para el consumo humano (Ordoñez, 2017; Gaceta LIX/1SPR-16/2432, 2004). Este tianguis de animales es considerado uno de los más grandes de México, por lo que es prioritaria la aplicación de la Ley Federal de Sanidad Animal y la Ley Federal sobre Metrología y Normalización en materia de ganadería.

También se ofertan productos orgánicos como frutas y verduras. Una práctica común en torno a este producto se da al terminar la jornada, ya que el precio queda sujeto al ofrecimiento del comprador, lo cual resulta en una disminución en el costo (Gómez et al., 2007). Existe la venta de comida y bebida típica de la región, así como, la comercialización de forrajes y semillas, venta de vehículos y accesorios agrícolas, artículos de reúso y chácharas (figura 3). Entre los servicios que se ofrecen dentro del tianguis están los terrenos destinados para estacionamiento, acceso a baños, casetas de vigilancia, administración y transporte vehicular de comunidades cercanas, de municipios y de la misma capital del Estado de México hacia el tianguis.

Un punto importante de mencionar es el comportamiento observado en el tianguis durante la época lluviosa. Como lo estipulan Malinowski y de la Fuente (1957), las lluvias vespertinas desorganizan las actividades. Asimismo, si son constantes en el día, resultan perjudiciales para el comercio y los pasillos de terracería se vuelven problemáticos por la presencia de encharcamientos y lodos, lo que dificulta la libre elección de mercancías y el tránsito peatonal. No obstante, si las condiciones son buenas durante esta misma época, suele incrementarse la venta de productos orgánicos como los derivados de la calabaza, maíz, frijol, trigo, hongos; en época de estiaje, aumenta la venta de forrajes como zacate, maíz en grano, alfalfa y trigo. En julio y agosto aumenta la comercialización de animales de establo, debido a las necesidades de flujo de dinero para la compra de útiles escolares y pagos de colegiaturas, según lo manifestado por personas encuestadas. 
Figura 3

Principales giros dentro del tianguis
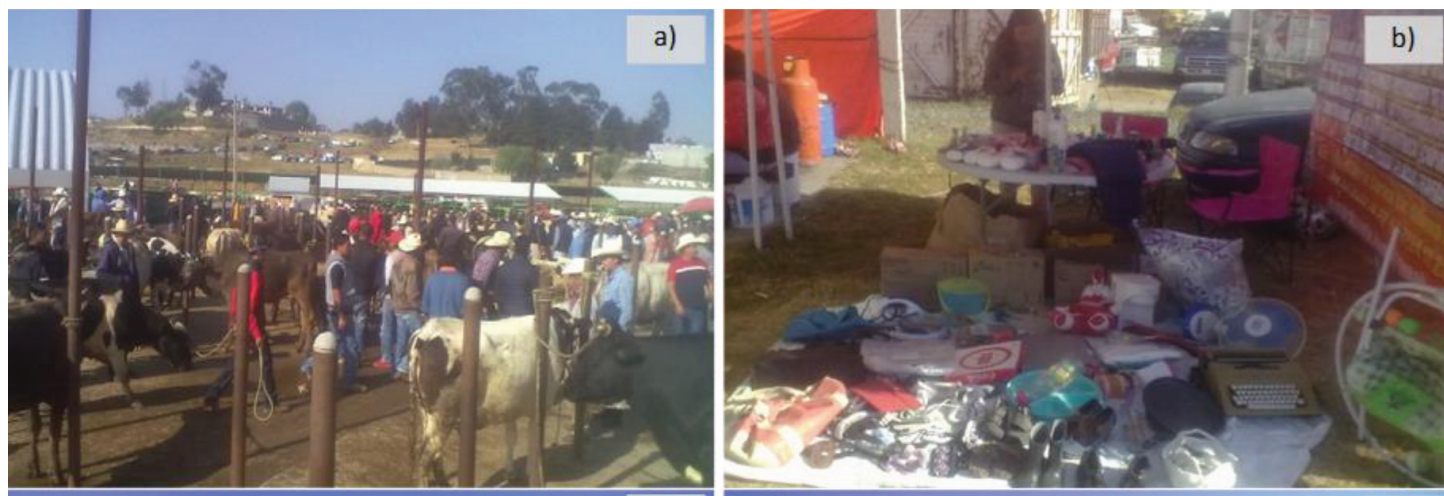

c)

d)
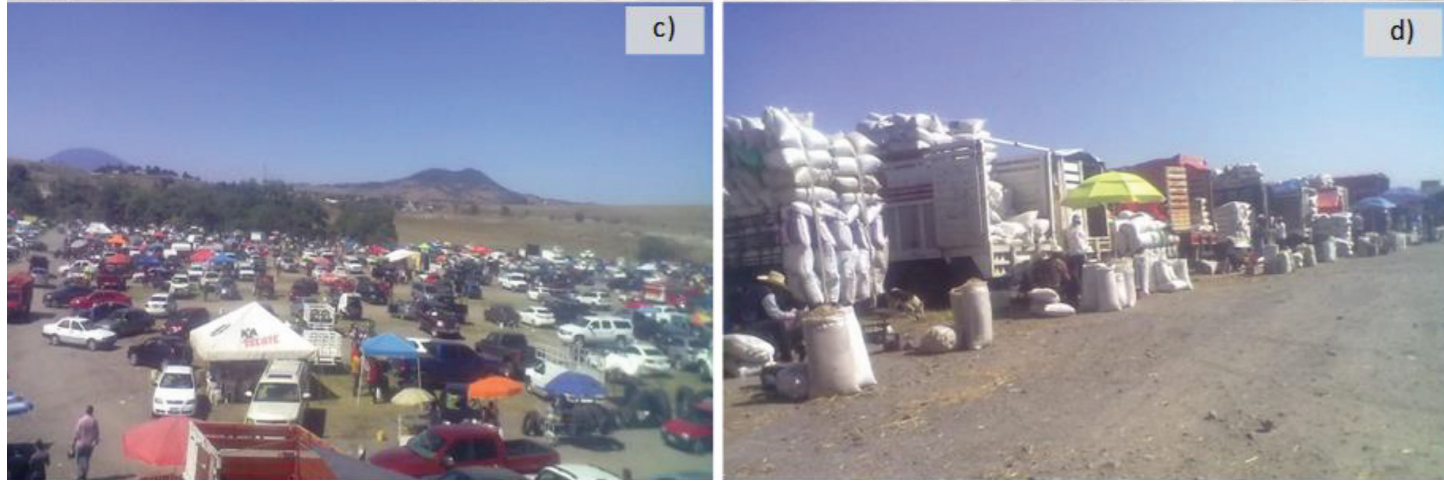

Nota: a) ganadero, b) chácharas (propio puesto instalado), c) automovilístico, d) forrajes, entre otros. Fotografías tomadas por los autores.

Al igual que el estudio realizado por Hernández et al. (2014), se encontró que el consumo o adquisición de cada sector del tianguis se caracteriza por el gusto del cliente, el precio $y$ la diversidad de productos. Malinowski y de la Fuente (1957) advirtieron que los clientes buscan artículos específicos, observan los puestos $y$ negocian, sin que se entrometan otros vendedores en el instante; esto mismo se registró al aplicar la metodología de involucramiento como parte del sistema en el puesto instalado (figura 3b). Desde este sitio se estudió el comportamiento del cliente, a la vez que se evaluó la volatilidad de precios, donde se advirtió que un mismo artículo de reúso en otros puestos presentó una variación del $10 \%$ al $30 \%$. Por tanto, esto lleva a la proposición de que las formas y medios de compra-venta e intercambio se rigen bajo racionalidad económica, al favorecer y conformar redes $y$ relaciones como estrategia económica. Como resultado, esto permite, como ocurre generalmente en los tianguis, que tanto las personas visitantes como las personas consumidoras, compradoras o vendedoras persistan y se adapten a las variaciones según las prácticas. Asimismo, esto genera una articulación metódica, que se sobrepone a la volatilidad de los precios fijados, la cual cada lunes genera una derrama económica para los vecinos y las vecinas locales y de la región, en palabras de las personas entrevistadas: "peor no vender nada".

De la forma anterior, los giros han llevado al desarrollo de diversos actores sociales que se ven involucrados, entre los que destacan: i) productores quienes ofertan sus productos a diversos precios (que en este caso se identificaron mayoritariamente a personas de bajos recursos), ii) los consumidores quienes generan 
la demanda en la compra de los insumos (personas de clase baja y media), iii) intermediarios o revendedores quienes generan implícitamente un ajuste de precios para obtener una ganancia, mediante una forma engañosa, iv) intercambiantes, quienes realizan el trueque o intercambio de productos diversos (el caso más general de productor a productor, generalmente personas de bajos recursos), v) vecinos aledaños que ofertan servicios utilizando sus bienes o medios a cambio de una remuneración económica (personas de clase media), $y$ vi) visitantes quienes por ocio o esparcimiento acuden sin un fin en específico (personas de clase media).

Cabe destacar que con los datos obtenidos de la encuesta, fue posible evaluar el perfil de cada uno de los actores, como lo muestra la tabla 2. Además, se determinaron las zonas de donde provienen las 200 personas encuestadas, en relación con el tipo de comercialización que llevan a cabo : i) comercialización de animales: Ixtlahuaca, Almoloya, Villa Victoria, San Felipe del Progreso, San José del Rincón y Temoaya, ii) comercio de orgánicos: Toluca, Xonacatlán, Temoaya, Ixtlahuaca, Atlacomulco, iii) comercio de alimentos: Ixtlahuaca, Toluca, Almoloya, Temoaya, iii) comercio de forrajes: Jiquipilco, Atlacomulco, Temoaya, iv) comercio de automóviles: Toluca, Metepec, Tenango, Zinacantepec, Atlacomulco, Ciudad de México, v) comercio de chácharas: Temoaya, Almoloya, Toluca, Ixtlahuaca, Metepec, Lerma, Zinacantepec. A partir de esto, en términos geográficos, los resultados muestran que el tianguis cubre el comercio de la zona norte del Valle de Toluca.

Tabla 2

Características de los actores dentro del sistema del tianguis y plaza Puente San Bernabé

\begin{tabular}{|c|c|c|c|c|}
\hline ROL & PRINCIPALES GIROS & $\begin{array}{l}\text { RANGO PROMEDIO } \\
\text { DE EDAD (AÑOS) }\end{array}$ & $\begin{array}{l}\text { RANGO DE } \\
\text { NIVEL DE } \\
\text { ESTUDIOS }\end{array}$ & $\begin{array}{l}\text { RECURRENCIA } \\
\text { PROMEDIO } \\
\text { (DÍAS) }\end{array}$ \\
\hline Productores & $\begin{array}{l}\text { Ganado, productos orgánicos, } \\
\text { alimentos, forrajes }\end{array}$ & $30-45$ & $\begin{array}{l}\text { Secundaria a } \\
\text { preparatoria }\end{array}$ & 8 \\
\hline Consumidores & $\begin{array}{l}\text { Ganado, productos orgánicos, } \\
\text { alimentos, forrajes, automóviles, } \\
\text { chácharas }\end{array}$ & $20-60$ & $\begin{array}{l}\text { Secundaria a } \\
\text { licenciatura }\end{array}$ & 8-15 \\
\hline $\begin{array}{l}\text { Intermediarios o } \\
\text { revendedores }\end{array}$ & $\begin{array}{c}\text { Ganado, automovilístico, } \\
\text { chácharas }\end{array}$ & $20-40$ & $\begin{array}{l}\text { Secundaria a } \\
\text { preparatoria }\end{array}$ & 8 \\
\hline Intercambiantes & Ganado, Productos orgánicos & $40-60$ & Primaria & 8 \\
\hline Vecinos & Estacionamientos & $40-60$ & Secundaria & 8 \\
\hline Visitantes & Chácharas & $15-45$ & $\begin{array}{l}\text { Secundaria a } \\
\text { licenciatura }\end{array}$ & 20 \\
\hline
\end{tabular}

Como se observa en la tabla 2 , el sector más desfavorecido es el de los intercambiantes, quienes manifestaron tener educación primaria y ser de edad más avanzada. Ellos realizan el trueque de sus productos, tales como: productos orgánicos (calabazas, frijol, maíz, trigo, frutas de temporada) o animales de corral (cerdos, borregos, conejos, gallinas y guajolotes 
principalmente). Los vecinos del lugar han sido los más favorecidos por la habilitación de espacios para estacionamiento, ya que lunes a lunes reciben remuneración por la ocupación. Los visitantes $y$ consumidores se constituyeron de personas de educación secundaria a universitaria avanzada (licenciatura). Así, los productores e intermediarios reportaron una educación básica $y$ media superior, y el rango promedio de edad fue de los 20-40 años. Además, la recurrencia al tianguis fue de 8 días (cada lunes).

Cabe resaltar que es necesario profundizar la actuación de los intermediarios o revendedores, ya que es un sector con prejuicios debido a que las prácticas no son bien vistas en este tipo de tianguis, por lo cual se presenta un nivel de incertidumbre de la información a obtener. Además de que estos actores han formado grupos en las principales entradas al mercado, lo que evidentemente es una muestra del control del precio sobre todo en lo referente a ganado vacuno y ovino, así como a la compraventa de vehículos.

\section{AFOROS PEATONALES}

La mayor afluencia peatonal se concentró en las orillas de las principales carreteras, mientras que en la intersección se observó un punto de conflicto que detuvo el tráfico hasta por $1 \mathrm{~km}$ con destino a Toluca por la carretera libre. Como resultado, los mismos sistemas de transporte no pueden cruzar y se ven obligados a retornar para buscar caminos de terracería alternos, como se observó en la figura $2 e$.

Quienes recurren al Tianguis no siguen un patrón definido de movilización. Su recorrido es motivado por los precios que resaltan a la vista, el sonido de las bocinas del merolico promocionando productos, el de las lonas al anunciar ofertas, música popular en los puestos y de acompañamiento por guitarristas que viajan desde lejos para tocar melodías a los comensales a cambio de una remuneración económica. Los compradores se detienen de forma inesperada a observar, lo cual genera que la gente invada las carreteras, así como la detención del tráfico: cruzan sin observar a los lados porque saben que el tráfico es lento o está obstaculizado, pero no hay sonido de claxon porque ya saben que cada lunes es así. Lo anterior ha generado riesgos derivados de la venta de ganado, instalación de puestos diversos a nivel de calle que obstruyen el paso, escasez de señalamientos, afluencia peatonal, con características de desorganización, lo cual genera riesgos viales en la zona (Ayuntamiento Constitucional de Almoloya de Juárez, 2008).

Gráficamente, para el aforo por la carretera a Mayorazgo de León, de 8:30 a.m. a 3:30 p.m. existe un incremento y decremento, respectivamente, de la afluencia peatonal. El pico más alto se obtuvo a mediodía, así, la máxima concentración se obtuvo para el día lunes de vacaciones de fin de año con una entrada cercana a las 3000 personas, próximas a 2000 para día feriado y de 1500 para lunes laboral (figura 4a). Para el lado norte (figura 4b), el incremento y decremento se obtuvo, respectivamente, de 9:00 a.m. a 4:30 p.m. La mayor concentración a mediodía, con un máximo cercano a 6000 personas para el lunes de vacaciones, 4100 en día feriado y 2400 personas en día laboral. En la zona sur se obtuvo una movilización incremento $y$ decremento de las 8:00 a.m. a las 5:00 p.m. En este caso, el pico se dio entre el mediodía $y$ las 2 p.m., con una afluencia cercana a 7200,5500 y 4000 personas para el lunes de vacaciones, días feriado $y$ día laboral, respectivamente (figura 4c). 
Figura 4

Aforo de afluencia peatonal

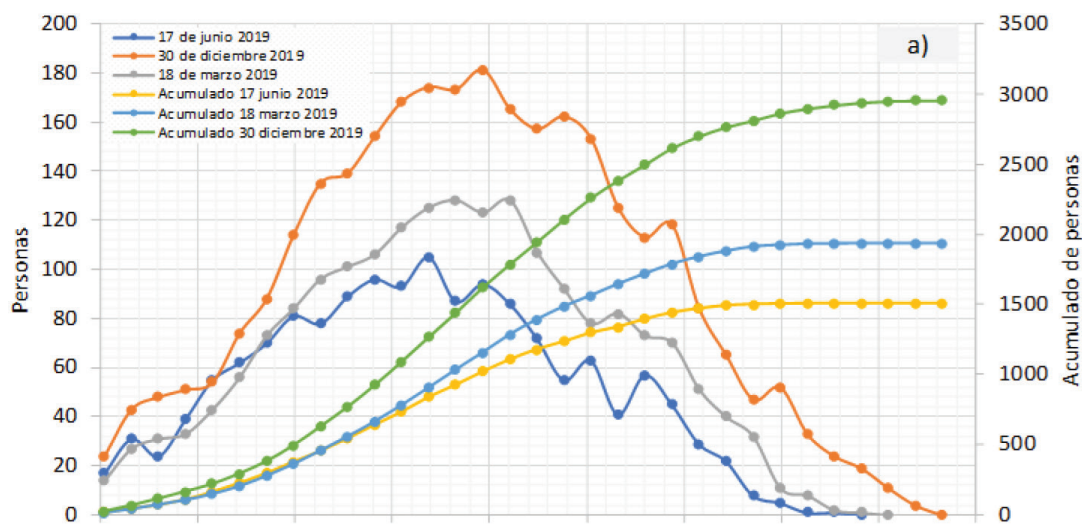

7:12a. m. 8:24a. m. 9:36a. m. 10:48a. m.12:00p. m. 1:12p. m. 2:24p. m. 3:36p. m. 4:48p. m. 6:00p. m. Tiempo (h)
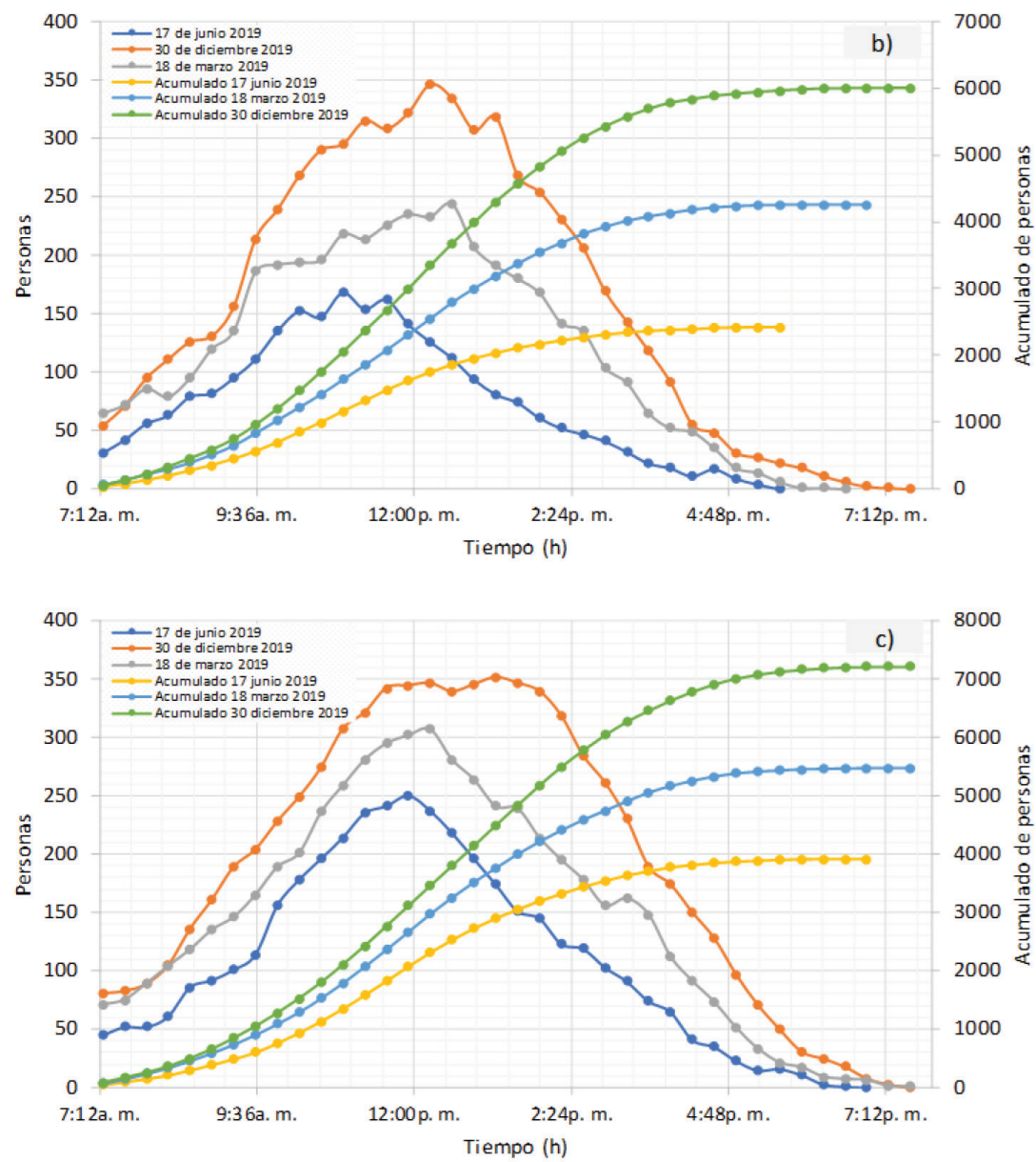

Nota: a) carretera a Mayorazgo de León, b) carretera libre Toluca-Atlacomulco zona norte, c) carretera libre Toluca Atlacomulco zona sur. 
La figura 4 muestra que en la época decembrina hay mayor movilización de peatones, lo cual puede atribuirse al ocio vacacional o a un mayor ingreso económico que permite realizar compras. En todos los casos, la mayor concentración se genera de 10 a 12 de la mañana. De forma particular se puede deducir que el mayor atractivo del tianguis es la zona destinada para la venta de artículos de reúso y chácharas, lo cual es un indicativo de que este tipo de comercio genera mayores entradas en comparación con los productos que originaron el tianguis, además que estos se pueden negociar por la diversidad existente de productos.

En resumen, en estos mercados semanarios hay un mayor despliegue de mercancías $y$ comercio en días festivos como navidad y semana santa, lo cual genera una mayor afluencia peatonal (Malinowski y de la Fuente, 1957). Cabe mencionar que en estas fechas es posible la atracción de visitantes a la plaza ganadera. Tomando en consideración lo establecido por Monterroso y Colin (2012), esto se debe a que los tianguis típicos, además de las fiestas tradicionales, pueden ser considerados como recursos turísticos culturales, gracias a la diversificación de productos comerciales como ocurre en el Tianguis de San Bernabé.

\section{CRECIMIENTO SUPERFICIAL}

El Tianguis del Puente San Bernabé ha sido un punto de encuentro por más de 70 años, con diversidad comercial que incluye: productores agrícolas, ganaderos, manufactureros, alimentaria, automotriz de uso y representantes de compañías industriales, quienes ofertan productos tecnológicos y de comunicación, incluso materiales, artículos o productos de reúso y chácharas.

De acuerdo con el análisis de datos obtenidos de las entrevistas a las personas vecinas de la zona, de la observación de los puntos de monitoreo y de las imágenes satelitales, fue posible generar la tabla 3, la cual muestra el crecimiento de la superficie del tianguis desde la década de los 50. El principal giro era la compra-venta de aves, por parte de vecinos de la zona, debido a que anteriormente la carretera Libre TolucaAtlacomulco era el principal punto de comunicación hacia la Ciudad de Toluca y de México.

Con base en los datos sobre aforo peatonal se obtiene una visita de 16169 personas como máximo para el año 2019, en función de la superficie ocupada. Se evaluó con una regresión la afluencia estimada para los años previos de análisis, con ello se pudo estimar que en los inicios del tianguis la afluencia aproximada fue de 191 personas. 
Tabla 3

Crecimiento superficial de comercialización y afluencia peatonal

Plaza Ejidal Puente San Bernabé

1950-2019

\begin{tabular}{|c|c|c|c|}
\hline AÑO & $\begin{array}{l}\text { SUPERFICIE DE } \\
\text { OCUPACIÓN (HA) }\end{array}$ & GIROS DE SERVICIOS, COMPRA-VENTA & $\begin{array}{l}\text { AFLUENCIA ESTIMADA } \\
\text { (PERSONAS) }\end{array}$ \\
\hline 1950’s & 0.5 & Aves de corral. & 191 \\
\hline 1990’s & 4.20 & $\begin{array}{l}\text { Aves de corral, ganado, estacionamientos, alimentos } \\
\text { y chácharas. }\end{array}$ & 1609 \\
\hline 2003 & 16.4 & $\begin{array}{l}\text { Aves de corral, animales domésticos, ganado, } \\
\text { estacionamientos, vehículos, alimentos, productos } \\
\text { orgánicos, forrajes y chácharas. }\end{array}$ & 6283 \\
\hline 2011 & 33.7 & $\begin{array}{l}\text { Aves de corral, animales domésticos, ganado, } \\
\text { estacionamientos, vehículos, alimentos, productos } \\
\text { orgánicos, forrajes, chácharas, ferretería y tlapalería. }\end{array}$ & 12912 \\
\hline 2015 & 38.4 & $\begin{array}{l}\text { Aves de corral, animales domésticos, ganado, } \\
\text { vehículos, alimentos, estacionamientos, productos } \\
\text { orgánicos, forrajes, chácharas, ferretería, tlapalería, } \\
\text { ropa y telefonía. }\end{array}$ & 14713 \\
\hline 2019 & 42.2 & $\begin{array}{l}\text { Aves de corral, animales domésticos, ganado, } \\
\text { vehículos, alimentos, estacionamientos, productos } \\
\text { orgánicos, forrajes chácharas, ferretería, tlapalería, } \\
\text { ropa, muebles, electrodomésticos y telefonía. }\end{array}$ & 16169 \\
\hline
\end{tabular}

En sus inicios, la superficie ocupada no era superior a los $5000 \mathrm{~m}^{2}$, donde cubría solo la parte del entronque de las carreteras. Por la década de los 90, la superficie creció hasta aproximadamente 4 hectáreas $y$, con ello, la comercialización de productos como animales de corral, alimentos y chácharas, además del servicio de estacionamientos. Con base en las imágenes satelitales, del 2003 al 2019 se obtuvo la superficie de ocupación. Según se observa en las imágenes, pasó de 16,4 hectáreas a las 42,2 hectáreas actualmente ocupadas, derivado de la variedad de productos que se comercializan cada lunes. En la figura 5 se muestra la distribución de la superficie según los principales giros del mercado, con lo cual el área destinada a estacionamientos ha sido uno de los negocios más rentables, seguida de la ocupación por artículos de reúso y chácharas; en tercer lugar, el espacio destinado a la compra-venta de vehículos, y el área de comercialización de ganado. En un espacio menor se encuentran la comercialización de forrajes, área de alimentos y bebidas, $y$ productos orgánicos. 
Figura 5

Evaluación y distribución de los diferentes giros del tianguis Puente San Bernabé en 2020

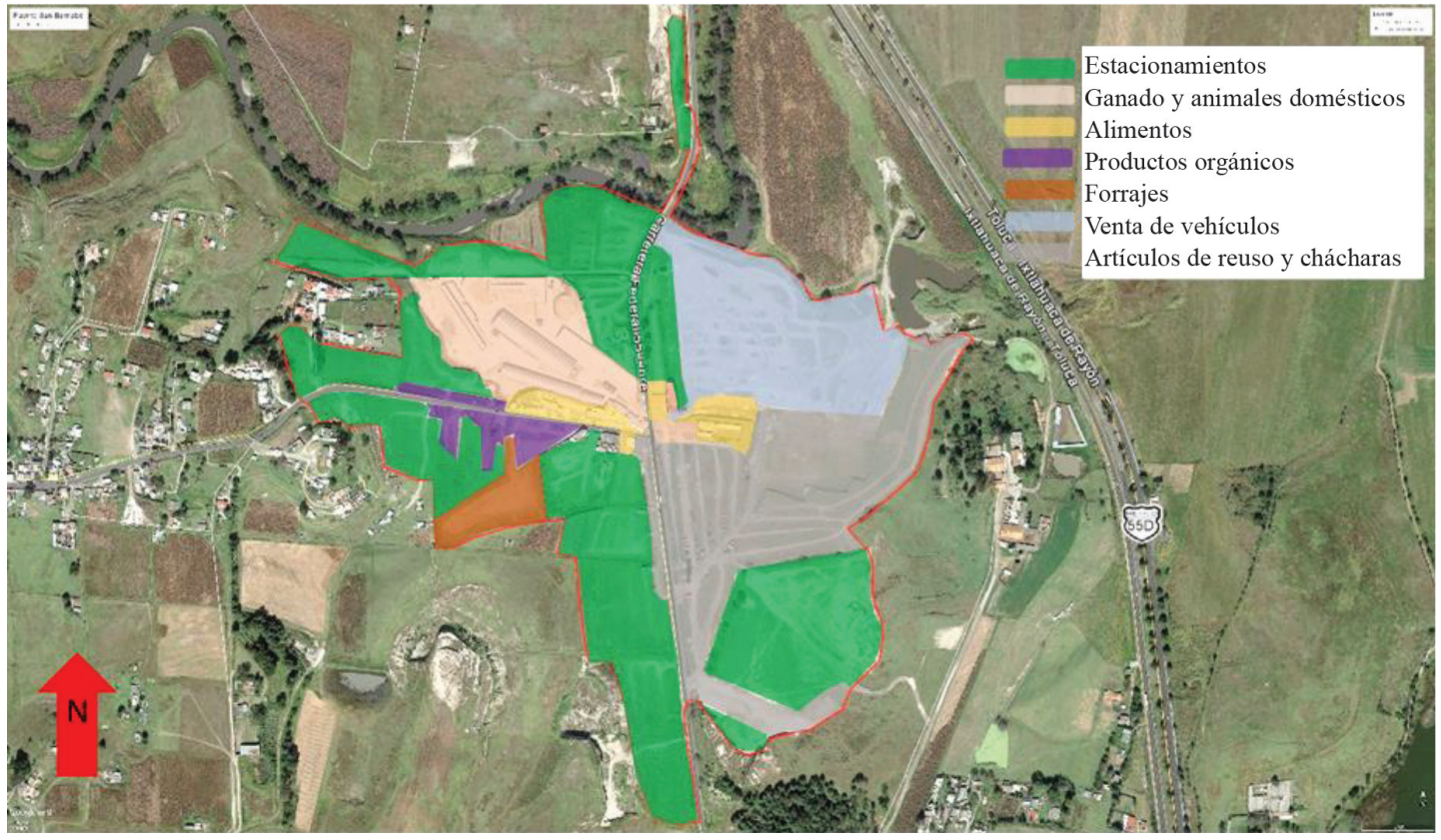

A pesar de la presencia de tianguis cercanos, como el de los viernes en Palmillas (Toluca), desde 2006 ubicado a $13 \mathrm{~km}$ y el de Ixtlahuaca a $14 \mathrm{~km}$ realizado el día lunes, el tianguis de San Bernabé sigue creciendo por la heterogeneidad de productos que se comercializan, la concurrencia de vecinos, visitantes, consumidores $y$ vendedores, aun por encima de la presencia de otros mercados cercanos como son: los martes en San Pedro de los Baños y Taborda, miércoles en San Cayetano, jueves en Cieneguillas y Tlachaloya, sábado en San Isidro y domingo en Rancho San Juan.

La necesidad, el consumo y el alcance económico se refleja en la oferta-demanda $y$, con ello, el crecimiento. El crecimiento acelerado en los últimos 17 años (figura 6) ha sido gracias a la diversidad de productos ofertados, el área disponible para generar servicios y la ubicación en el centroide del corredor Toluca-tlacomulco, con lo que las comunidades cercanas y otras más alejadas, tienen accesibilidad para ofertar o consumir productos a precios accesibles.

En la figura 6 se muestra el crecimiento acelerado del tianguis, a pesar del cobro por la renta de espacios para venta de productos. A saber, en espacios de aproximadamente de $3 \mathrm{~m} \times 3 \mathrm{~m}$ el costo es de 50 pesos, mientras que el estacionamiento oscila entre 15 y 20 pesos tiempo libre, aunque también hay ofertantes de servicios y productos que se rigen parcial o libremente. 
Figura 6

Crecimiento superficial de ocupación y afluencia peatonal estimada en función del tiempo de existencia de la Plaza Ganadera Ejidal Puente San Bernabé

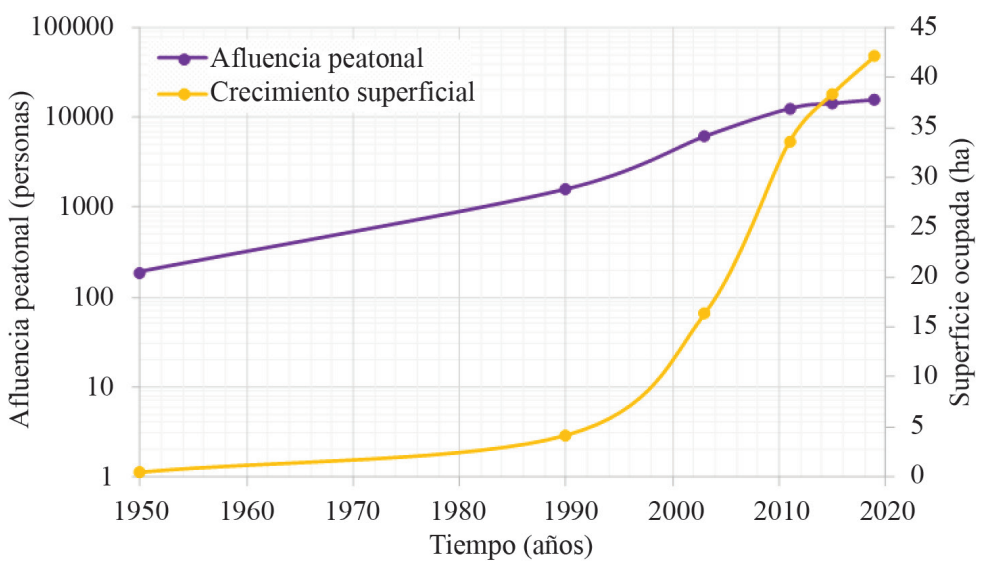

El tianguis tiene una cobertura de 8 horas generalmente; en términos brutos, suele anticiparse poco antes de la madrugada $y$ extenderse por la tarde, como los lunes feriados. Así mismo, esto permite la rotación de personas y productos para quienes inician desde muy temprano. Existe organización interna, derivado de la participación de las diferentes personas, ha permitido establecer espacios definidos y particulares según el tipo de producto o el giro de mercancías con la finalidad de controlar y regularizar el cobro de espacios otorgados por los propietarios a los vendedores. Lo anterior asociado a otros sitios permite equidad y democracia, además de que genera credibilidad respecto al proceso de producción y comercialización (Roldán, 2014).

Como en la mayoría de los sitios comerciales a cielo abierto, al final de día fue evidente la presencia de desechos de tipo orgánico e inorgánico, residuos líquidos, sólidos y gaseosos, asociados a la disposición final una vez realizada la recolección y quema al día siguiente. En este contexto, al igual que en otros tianguis, dadas las características de comercialización y naturaleza de los bienes, esto debe propiciar la implementación de programas tendientes al reciclaje (Buenrostro et al., 1999).

\section{MODELO CONCEPTUAL}

La competitividad que sufren este tipo de tianguis con centros comerciales establecidos, puede influir más sobre los riesgos para la salud, las formas de producción, procesamiento y comercialización (Escalona, 2009), o bien, se da una marginación por esta modalidad a pesar de ser un eje de articulación de las economías urbano-populares, campesinas e indígenas (González y Vega, 2016). Sin embargo, el Tianguis del Puente San Bernabé no deja de crecer a pesar de la competitividad y de la marginación, de estar en una zona rural $y$ de sufrir embates del regateo para la compra de productos a lo que son sujetos este tipo de mercados. De hecho, la diversificación de bienes y productos a través del tiempo, así como, la integración han sido claves en el crecimiento global del área del Tianguis del Puente San Bernabé.

Adicionalmente, a pesar de la presencia de intermediarios o revendedores, el mecanismo organizacional ha generado circuitos cortos; es decir, al reducirse la distancia entre productores y consumidores, solo es posible la presencia de un intermediario (García et al., 2016). Como consecuencia, esto genera formas variadas de relacionarse (directas o indirectas, individuales o colectivas), entre productores y consumidores. Lo anterior se da debido a que 
al ampliarse sustancialmente el mercado, esto genera la posibilidad de no ser partícipe de los hechos que estos grupos realizan para la competitividad, posiblemente aumentando con ello la confianza entre productor y consumidor.

Como se ha demostrado en esta investigación y de acuerdo con lo que exponen Fabre y Egea (2015), el tianguis es un mecanismo a través del cual muchas personas generan redes de comunicación, lo cual propicia el desarrollo de estrategias dinámicas para la comercialización, a pesar de que generalmente estas son impuestas por el mercado. De este modo, la presente investigación evidencia los contrastes entre lo urbano y lo rural, así como las prácticas que han persistido por varios años y que pueden considerarse como una costumbre.
Así, entonces, existen tres agentes principales: la sociedad, los productores y los consumidores que tiene en común necesidades $y$ las cubren mediante la oferta $y$ demanda de productos, donde la diversificación de artículos, productos y servicios genera volatilidad de precios, lo que provoca un aumento en el número de visitantes $y$ de consumidores. Los precios accesibles permiten el retorno de los anteriores, con lo cual incrementa la competitividad por los clientes y, con ello, más productos y la necesidad de mayores espacios para la comercialización. Lo anterior se muestra en la Figura 7, y se puede verificar al aplicar un ciclo rotativo del modelo para el crecimiento actual de acuerdo con los datos obtenidos.

Figura 7

Modelo conceptual para el crecimiento comercial del Tianguis

Plaza Ejidal Puente San Bernabé Almoloya de Juárez

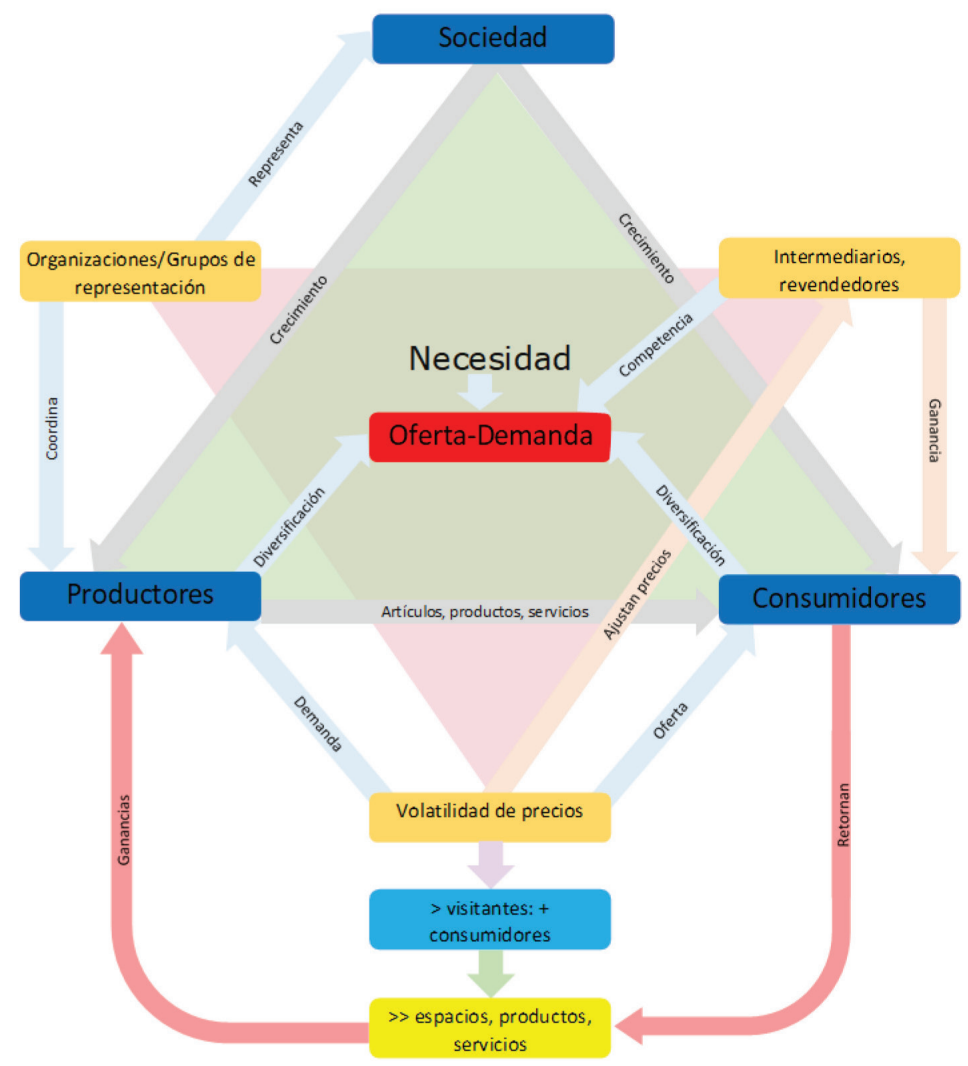


De esta forma, el actual tianguis funge como un eje central para el comercio de la región, con insumos que surgen de la necesidad, lo cual ha sido el principal factor que ha generado la amplia diversificación, tal que no solo asista el consumidor, sino también quien desee el esparcimiento. Lo anterior se da debido al incremento de sistemas de transporte suburbano $y$ colectivo para mantener comunicado al tianguis con las diversas localidades aledañas.

Tal como lo indican Malinowski y de la Fuente (1957), la desaparición de los mercados implicaría mayores gastos o recorridos de distancias mayores hacia otros centros comerciales para los comerciantes, visitantes y demás personas que dependen de estos mercados para obtener o comercializar productos. En este caso, la población cercana tendría que trasladarse al tianguis de Ixtlahuaca o al mercado de Palmillas, con la consideración de que en estos la venta de productos es diferente a la comercializada en el tianguis de la plaza ejidal Puente San Bernabé.

De acuerdo con Schlack et al. (2018) es difícil describir todas las características físicoespaciales $y$ de administración para declinar políticas públicas y diseño urbano, pero bien existe accesibilidad a nivel regional por diferencia de productos, lo que permite atraer usuarios diversos y esto genera el carácter público del espacio. A pesar de que estos espacios de oferta-demanda están alejados de las políticas públicas, no dejan de ser una fuente importante para la generación de crecimiento y desarrollo económico rural, ya que ofrecen oportunidades comerciales con la generación de empleo, autoconsumo e intercambio. Además, muestran una imagen de la diversidad biocultural de un sitio, una zona, una comunidad o región, y son propios del medio en que se desarrollan (Argueta, 2016). De esta forma, aunque actualmente se han desarrollado aplicaciones mediante el uso de las Tecnología de la Información y la Comunicación para la visualización estética como mejora urbana para el diseño de puestos ambulantes (Redondo et al., 2016), el tianguis popular es una forma de manifestación sociocultural que permite identificar una región a través de la comercialización de productos y de la gente que acude a ello, tal como se ha percibido en este trabajo de investigación.

\section{CONCLUSIÓN}

Los giros comerciales del Tianguis y la Plaza del Puente de San Bernabé son el principal factor que ha permitido su permanencia, evolución y crecimiento. Aunado a esto, se ha creado una amplia y compleja red de economía como motor de supervivencia para las regiones rurales cercanas a pesar de la marginación, de la competitividad con mercados cercanos, de las malas prácticas y de ubicarse en una zona rural.

Los principales protagonistas son los productores, los consumidores, los intercambiantes o los intermediarios, los vecinos y los visitantes, quienes juega un rol según la diversidad de productos, artículos y servicios que se ofertan y demandan. Como consecuencia se siguen integrando redes, cuyo futuro estudio podría definir un perfil particular de cada una de estas, así como la manera en que influyen en el mercado, desde la selección de artículos hasta la volatilidad de precios. El actor más vulnerable es quien aún intercambia sus productos, el agente más favorecido son los vecinos con la renta de espacios y quienes obtienen ganancias no controladas son los revendedores o los intermediarios.

El actual Tianguis de San Bernabé es una manifestación sociocultural propia del sitio $y$ de la región centro norte del Valle de Toluca. Al ser una imagen clara de la costumbre y tradición, en las vacaciones de fin de año es visible una mayor afluencia de personas que acuden a este sitio, principalmente como consumidores 0 visitantes.

Como se indicó anteriormente, el Tianguis inició a causa de las necesidades de compra-venta de animales corral y domésticos por parte de los vecinos de la zona. Con el paso del tiempo, la disponibilidad de espacios libres, las interconexiones viales y el acceso a los precios han generado que se integren nuevos productos de comercialización y, con ello, la diversificación. En consecuencia, el Tianguis se ha convertido en un gran atractivo para personas de otras regiones. 
El modelo muestra que las necesidades de la sociedad han influido en la diversidad de oferta-demanda como el principal motor de evolución y crecimiento del tianguis. Asimismo, se observa que las fluctuaciones de ingreso-egreso están en función de la afluencia peatonal, la cual, a su vez, dependen de cada lunes del año. De tal manera, el modelo conceptual es una integración social con el entorno productivo $y$ comercial en donde los espacios físicos son el recurso ideal para el crecimiento ocupacional. Como resultado, así como se registra en el sitio de estudio, esto genera compra-venta al aire libre.

Por último, como recomendación para futuras investigaciones, es necesario estudiar internamente subsistemas, que permitan describir los procesos como redes económicas. Al considerar que estas pueden convertirse en redes complejas que permiten entender las formas en que se favorecen los sectores involucrados en función del perfil de cada uno de estos.

\section{REFERENCIAS}

Almazán, F. R. M. (2017). Reubicación del comercio informal en el mercado "Lic. Benito Juárez García” de la Ciudad de Toluca. [Tesis de Licenciatura]. Facultad de Ciencias Políticas y Sociales, Universidad Autónoma del Estado de México, México.

Aranda, S. J. M. (2005). Terciarización y precarización del trabajo en la Zona Metropolitana de Toluca, 1980-2000. Papeles de Población, 46, 109-137.

Arellanes, C. Y., Arellanes, C. N. y Ayala, O., D. A. (2017). El tianguis de cambio de Pátzcuaro, Michoacán, a través del metabolismo social desde Mesoamérica hasta el siglo xxi. Estudios Sociales Revista de Alimentación Contemporánea $y$ Desarrollo Regional, 50(27), 1-30.

Ayuntamiento Constitucional de Almoloya de Juárez (2016). Plan de Desarrollo Municipal 2016-2018 de Almoloya de Juárez, México.

Ayuntamiento Constitucional de Almoloya de Juárez (2008). Plan Municipal de Desarrollo Urbano de Almoloya de Juárez, México.
Argueta, V. A. (2016). El estudio etnobioecológico de los tianguis y mercados en México. Revista Etnobiología, 14(2), 38-46.

Arteaga, B. N. (1993). Pluralidad cultural en la zona sur del Valle de Toluca. Convergencia Revista de Ciencias Sociales, 1, 45-63.

Buenrostro, O., Bernache, G., Cram, S. y Bocco, G. (1999). Análisis de la generación de residuos sólidos en los mercados municipales de Morelia, México. Rev. Int. Contam. Ambient., 15(1), 37-32.

Bustamante-Lara, T. I. y SchwentesiusRindermann, R. (2018). Perfil y situación de los productores que integran los tianguis y mercados orgánicos en México. Agricultura, Sociedad y Desarrollo, 507-530.

Córdova, J. E., López, C. A., Chavaria, S. H. $y$ de Aluja, A. S. (1997). Informe anual de las actividades realizadas por las clínicas ambulatorias en el periodo de julio de 1996 a junio de 1997. Vet. Méx., 28(4), 359-363.

Cruz, L. A. (2003). La fuerza de tracción animal en el medio rural mexicano. En C. Arriaga et al. (eds), Investigación en animales de trabajo para el desarrollo rural. (31-78 pp). Universidad Autónoma del Estado de México. México.

Díaz, G. E. P., Valladares, C. B., Gutiérrez, C. A. C. Arriaga, J. C. M., Quintero-Salazar, B., Cervantes, A. P. y Velázquez, O. V. (2017). Caracterización de queso fresco comercializado en mercados fijos $y$ populares de Toluca, Estado de México. Rev Mex Cien Pec, 8(2), 139-146.

Escalona Aguilar, M. A. (2009). Los tianguis $y$ mercados locales de alimentos ecológicos en México: su papel en el consumo, la producción y la conservación de la biodiversidad y cultura. [Tesis Doctorall. Universidad de Córdoba. Córdoba, España.

Escobar-López, S. F., Vizcarra-Bordi, I., ThoméOrtiz, H. y Espinoza-Ortega, A. (2016). Mercados y Tianguis de alimentos orgánicos en el centro de México: una opción de desarrollo económico y social. III 
Seminario "alimentos e manifestacoes culturais tradicionais”, II Simpósio Internacional "Alimentacao e inovacao na producao e consumo de alimentos". 203-210.

Fabre, P. D. A. y Egea, J. C. (2015). Los espacios de intercambio. Los tianguis de Pátzcuaro (Michoacán, México), entre la tradición y las estrategias de supervivencia. Documents d’Análisi Geográfica, 61(2), 265-287.

Gaceta LIX/1SPR-16/2432. (2004). Dictamen del punto de acuerdo en relación al mercado de San Bernabé, Almoloya de Juárez, en el Estado de México. Tercera comisión Hacienda y Crédito Público Agricultura y Fomento, Comunicaciones y Obras Públicas. Gaceta de la Comisión Permanente. Senado de la República, México.

García, B. R., Rappo, S. E. y Temple, L. (2016). Innovaciones socioambientales en el sistema agroalimentario de México: los mercados locales alternativos (tianguis). Agroalimentaria, 22(43), 103-117.

García, C. M., Liber, G. J. y Sosa, S. M. (2017). Guía para el desarrollo de mercados de productores. Organización de las Naciones Unidas para la Alimentación y la Agricultura. Ciudad de México, México.

Gómez, P. M., Gómez, V. M., Angón, M. P. y Castro, P. L. (2007). Comercialización de hongos silvestres comestibles en los mercados y tianguis de Morelia, Michoacán. Biológicas, 9, 81-86.

González, O. F. y Vega, B. S. (2016). Mercados itinerantes. Estudio comparativo de dos mercados en México. Revista de Ciencias Sociales, 1(151), 127-149.

Hernández, J. E., Carreón, L. L., Camacho, J. C., Franco, F. J. y Hernández, R. D. (2014). Producción y mercadeo de carne caprina en una región silvopastoril de la mixteca poblana, México. Revista Mexicana de Agronegocios, 35, 1043-1051.
Licona, V. E. (2014). Un sistema de intercambio híbrido: el mercado/tianguis la Purísima, Tehuacán-Puebla, México. Antipod. Rev. Antropol. Arqueol, 18, 137-163.

López, C. A., Villalba, M. y de Aluja, S. (1994). Actividades de las clínicas ambulantorias IDPT-ILPH-UNAM durante junio de 1992 a junio de 1993. Vet. Méx., 25(1), 55-59.

Malinowski, B. y de la Fuente, J. (1957). La economía de un sistema de mercados en México. Acta Antropológica, 1(2), 1-194.

Monterroso, S. N. y Colin, M. I. (2012). Construcción de servicios turísticos a nivel local en Toluca, Estado de México. Revista Rosa dos Ventos, 4(2), 119-135.

Ordoñez, M. L. (2017). Determinación de la prevalencia de Cryptosporidium spp. En ovinos menores de un año de edad en cuatro plazas comerciales del Estado de México. [Tesis de Licenciatura]. Universidad Autónoma del Estado de México, México.

Quezada, N. (1995). Congregaciones de indios y grupos étnicos: el caso del Vall de Toluca y zonas aledañas. Revista Complutense de Historia de América, 21, 141-165.

Redondo, E., Fonseca, D., Valls, F. y Olivares, A. (2016). Enseñanza basada en dispositivos móviles. Nuevos retos en la docencia de la representación arquitectónica. Caso de estudio: los tianguis de Tonalá, Jalisco, México. Expresión Gráfica Arquitectónica. Doi: 10.4995/ ega.2016.4730

Roldán, H. N. (2014). La construcción social de los mercados alternativos en México. Estudio de tres casos en distintos contextos y procesos de consolidación. [Tesis de Maestría]. El Colegio de la Frontera Sur. Quintana Roo, México.

Rubio, F. B. (2013). Los tianguis de la Ciudad de México en el siglo xvi. Anales de Museo de América XXI, 160-173.

Sales, C. J. y Martínez, S. T. (2014). Los talleres familiares $y$ el tianguis de Chiconcuac, México: un sistema económico sustantivo. Perspectivas Latinoamericanas, 11, 42-57. 
Schlack, E. E., Hidalgo, N. R., Villarroel, K., Arce, M. J. y Fariña, C. (2018). Tres tipos de comercio tres maneras de influenciar la esfera pública de los barrios. Revista INVI, 33(92), 89-122.

Smith, A. (1794). Investigación de la naturaleza y causas de la riqueza de las naciones. Tomo I, Valladolid.
Villegas, P. (2010). Del tianguis prehispánico al tianguis colonial: lugar de intercambio y predicación (siglo xvI). Estudios Mesoamericanos, 8, 93-101.

Fecha de ingreso: 30/03/2020 Fecha de aprobación: 14/10/2021 
